\title{
Next-generation des-r-carboxy prothrombin for immunohistochemical assessment of vascular invasion by hepatocellular carcinoma
}

Shintaro Yamazaki ${ }^{1 *}$ D, Tadatoshi Takayama ${ }^{1}$, Tomoharu Kurokawa ${ }^{1}$, Naoaki Shimamoto ${ }^{1}$, Yusuke Mitsuka ${ }^{1}$, Nao Yoshida ${ }^{1}$, Tokio Higaki ${ }^{1}$ and Masahiko Sugitani ${ }^{2}$

\begin{abstract}
Background: We have previously shown the value of next-generation des-r-carboxy prothrombin (NX-DCP) for predicting vascular invasion in hepatocellular carcinoma (HCC). Since conventional DCP is inaccurate under some conditions, this study aimed to assess whether NX-DCP immunohistochemical staining was related to vascular invasion in HCC.

Methods: Fifty-six patients scheduled to undergo resection for single HCC were divided into two groups, with and without pathological portal vein invasion. Immunohistochemical features of HCC and sites of vascular invasion were assessed using alpha-fetoprotein (AFP), conventional DCP, and NX-DCP.

Results: Pathological portal vein invasion was absent in 43 patients and present in 13 patients. Patient characteristics, pathological background of the liver parenchyma, and tumor-related factors did not differ significantly between the groups. There was no significant difference in the serum AFP level between the groups, whereas levels of conventional DCP $(p<0.0001)$ and NX-DCP $(p<0.0001)$ were significantly higher in the vascular invasion group. Immunohistochemical staining showed no significant difference in the staining rate of tumor (67.9\% vs. $80.7 \%, p=0.08)$, but NX-DCP stained significantly more at the sites of vascular invasion $(15.4 \%$ vs. $46.2 \%$, $p=0.01$ ) than conventional DCP. No vascular invasion was stained by AFP.
\end{abstract}

Conclusions: NX-DCP offers better sensitivity for detecting sites of vascular invasion than AFP and conventional DCP.

Keywords: Des-r-carboxy prothrombin, Alpha-fetoprotein, Vascular invasion, Hepatocellular carcinoma

\footnotetext{
* Correspondence: yamazaki-nmed@umin.ac.jp

'Departments of Digestive Surgery, Nihon University School of Medicine,

30-1 Ohyaguchikami-machi, Itabashi-ku, Tokyo 173-8610, Japan

Full list of author information is available at the end of the article
}

(c) The Author(s). 2020 Open Access This article is licensed under a Creative Commons Attribution 4.0 International License, which permits use, sharing, adaptation, distribution and reproduction in any medium or format, as long as you give appropriate credit to the original author(s) and the source, provide a link to the Creative Commons licence, and indicate if changes were made. The images or other third party material in this article are included in the article's Creative Commons licence, unless indicated otherwise in a credit line to the material. If material is not included in the article's Creative Commons licence and your intended use is not permitted by statutory regulation or exceeds the permitted use, you will need to obtain permission directly from the copyright holder. To view a copy of this licence, visit http://creativecommons.org/licenses/by/4.0/. The Creative Commons Public Domain Dedication waiver (http://creativecommons.org/publicdomain/zero/1.0/) applies to the data made available in this article, unless otherwise stated in a credit line to the data. 


\section{Background}

Des-r-carboxy prothrombin (DCP), known as proteininduced vitamin $\mathrm{K}$ absence or antagonist-II (PIVKA-II), is a biomarker for hepatocellular carcinoma (HCC) offering sensitivity of $40-56 \%$ and specificity of $81-98 \%$ [1-6]. The serum DCP level is considered more specific than alpha-fetoprotein (AFP) for malignant potential in $\mathrm{HCC}$, but the diagnostic powers of the two markers do not overlap [6-8]. Conventional DCP has not become a commonly used marker because the value is not accurate in the presence of vitamin $\mathrm{K}$ deficiency, the use of anticoagulants, or poor nutritional status associated with alcoholic abuse or jaundice [9-12]. Therefore, the nextgeneration DCP (NX-DCP) was created to improve on the disadvantage of having to use two different antibodies (P-11 and P-16) [9-16]. The diagnostic accuracy of NX-DCP for HCC under various conditions has been shown in previous studies [9, 11, 15, 17]. NX-DCP is thus considered a useful biomarker for clinical use.

The local recurrence of HCC depends on tumor diameter, vascular invasion, and intrahepatic metastasis via the portal vein $[2,18,19]$. Of them, vascular invasion has the highest risk for recurrence [7, 18-20]. Therefore, anatomic resection for $\mathrm{HCC}$ had been performed to treat microvascular invasion [21]. However, there have been numerous studies of detecting microvascular invasion preoperatively, but there has not yet been a definitive study $[22,23]$.

Recently, owing to the development of gene analysis, $\mathrm{HCC}$ with microvascular invasion has been divided into less invasive and highly invasive phenotypes associated with two distinct gene-expression profiles [8]. Similarly, some studies have mentioned that the up-regulation of some genes and pathways such as aurora kinase B predicts a worse outcome $[8,24,25]$. These genes are closely related to vascular invasion. Thus, the clarification of the mechanisms underlying vascular invasion is important for determination of treatment strategies and early detection of recurrence.

We have already shown the better predictive value of NX-DCP for detecting vascular invasion compared to alpha-fetoprotein (AFP) [17]. That study showed that NXDCP offered sensitivity of $71.4 \%$ and 1 -specificity of $13.1 \%$ for predicting vascular invasion, with an area under the curve of 0.813 . However, pathological information regarding NX-DCP remains limited, and no studies focusing on sites of vascular invasion as determined by immunochemistry have been reported. The aim of this study was to assess the value of NX-DCP for predicting vascular invasion in immunohistological studies.

\section{Methods}

\section{Patients}

Data of 61 patients who underwent liver resection for single pathologically confirmed HCC were collected. Five patients with $\mathrm{HCC}$ exceeding $50 \mathrm{~mm}$ in diameter were excluded, because large tumors have shown significant associations with vascular invasion [17]. Patients were divided into two groups, positive and negative for vascular invasion, according to the presence or absence of pathological portal vein invasion. Previous studies have shown that DCP levels were correlated with the degree of fibrosis, hepatitis, and warfarin pharmacotherapy $[9-11,16]$. To avoid false positives, only patients with a single HCC less than $50 \mathrm{~mm}$ in diameter who were not on warfarin were examined.

\section{Tumor marker analysis}

Blood samples $(6 \mathrm{~mL})$ were obtained from patients under general anesthesia before operation. The novel mouse anti-human DCP antibodies P11 (conventional DCP) and P16 (NX-DCP) were used. NX-DCP was analyzed from concentrated sera using the sandwich ECLIA method, with the assay system provided by EIDIA Co. (Tokyo, Japan) $[10,12]$. Informed consent was obtained from all patients, and the study protocols were approved by the scientific committee in our hospital (RK-130308-12).

\section{Histopathological study}

All resected specimens were cut into 10-mm-thick slices. Slices showing visible vessels were sectioned longitudinally and fixed in $10 \%$ formalin. Two independent pathologists inspected these fixed specimens, and all possible metastases and areas of vascular invasion were trimmed for embedding in paraffin blocks. Next, 5- $\mu$ m-thick sections for microscopy were stained with hematoxylin and eosin (HE). All areas of tumor were checked by two independent researchers (an expert pathologist, M.S., and a researcher for this study who was blinded to clinical data at inspection, T.K.) using HE staining to identify pathological portal vein invasion. Glisson's sheath was found close to the tumor or was hard to discriminate from vascular invasion, so Elastica van Gieson staining was additionally performed (Fig. 1). Vascular invasion was defined by the presence of clusters of cancer cells in the vascular space linked by endothelial cells. When Glisson's sheath was invaded and the structure was partially destroyed by cancer cells or the fibrous capsule surrounding the tumor was infiltrated by cancer cells, the serial microscopic sections were stained to confirm false positives. Regarding the evaluation of the background liver parenchyma, the New Inuyama classification was used to assess the degree of fibrosis in the liver (grade 0-4) and inflammation (grade 0-3) [26].

\section{Immunohistochemical staining}

When vascular invasion was identified on HE staining, AFP staining, conventional DCP staining, and NX-DCP staining were added, 3 slides per patient (Fig. 2A, B). Immunohistochemical staining for tumor and at sites of 


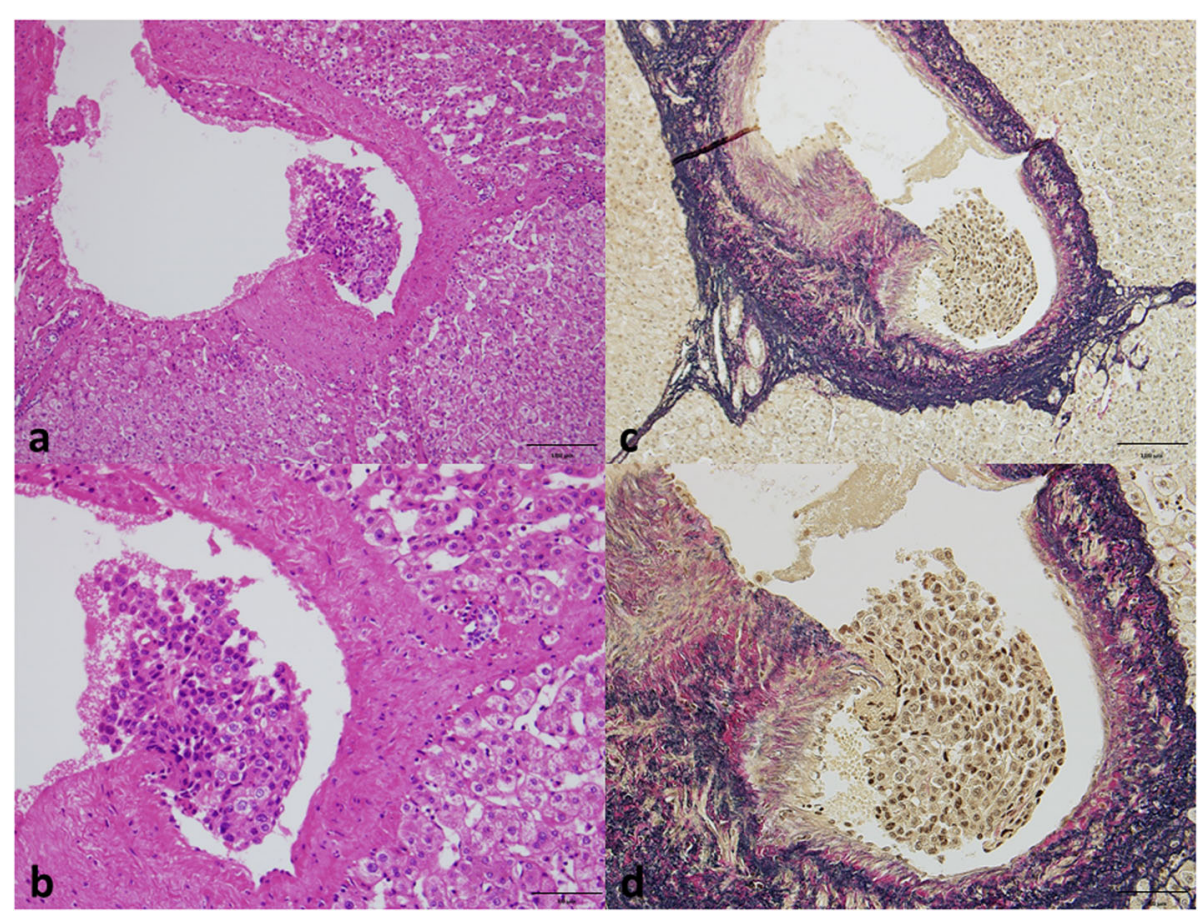

Fig. 1 Elastica van Gieson staining for vascular invasion. When vascular invasion was suspected on hematoxylin and eosin staining (a, b), Elastica van Gieson staining was performed (c, d). (Original magnification: $\mathbf{a}, \mathbf{c} ; \times 200, \mathbf{b}, \mathbf{d} ; \times 400$ )

vascular invasion was performed automatically using a Discovery XT system (Ventana Medical Systems, Tucson, AZ) using the Research IHC DAB MapXT procedure. Paraffin was melted at $70{ }^{\circ} \mathrm{C}$ for $30 \mathrm{~min}$, followed by $10 \mathrm{~min}$ at room temperature. Slides were incubated for $1 \mathrm{~h}$ at $37^{\circ} \mathrm{C}$ after a mild Ribo CC solution with a citratebased buffer ( $\mathrm{pH}$ 6.0) (Ventana Medical Systems). After rinsing, slides were incubated at $37^{\circ} \mathrm{C}$ for $42 \mathrm{~min}$ with a 1:100 dilution of AFP, 1:100 dilution of conventional DCP (MU-3), or 1:250 dilution of next-generation DCP (P-16) (Eidia Co., Tokyo, Japan). Slides were incubated with biotinylated goat anti-mouse immunoglobulin (Ig) $\mathrm{G}$ and IgM secondary antibodies for $8 \mathrm{~min}$, followed by incubation with proprietary Blocker D (Ventana Medical Systems) for $4 \mathrm{~min}$. Slides were then counterstained for 4 min with hematoxylin and rinsed. After removal from the instrument, slides were manually dehydrated and coverslipped.

\section{Statistical analysis}

Continuous variables were compared using Student's $t$ test or the Mann-Whitney U test. Multiple comparisons were made using repeated-measures analysis of variance. Significance was defined as values of $p<0.05$. All analyses were performed using JMP version 13.1 software (SAS, Chicago, IL).

\section{Results}

\section{Comparison of patients' characteristics by pathological} vascular invasion

In the total of 56 participants, pathological portal vein invasion was present in 13 patients (positive vascular invasion group) and absent in 43 patients (negative vascular invasion group) during the study period. No significant differences in rate of hepatitis virus infection, basic liver function, platelet count, and coagulation activity were evident between the groups (Table 1). Regarding background liver parenchyma, no significant differences between groups were seen in either pathological grade of liver parenchyma $(p=0.07)$ or degree of hepatitis $(p=0.33)$.

As for tumor-related factors, diameter did not differ significantly, but it tended to be smaller in the negative vascular invasion group [median: $28 \mathrm{~mm}$ (ranged: 11-50 $\mathrm{mm}$ )] than in the positive vascular invasion group [median: $22 \mathrm{~mm}$ (ranged: 9-38 mm), $p=0.06$ ]. Welldifferentiated tumor was more frequent in the negative vascular invasion group (20.9\%) than in the positive vascular invasion group $(0 \%, p=0.02)$, but no difference was identified in the frequency of poorly differentiated tumors $(p=0.38)$. No significant differences were apparent in the presence of fibrous capsule infiltration of the tumor $(p=0.89)$. 
A

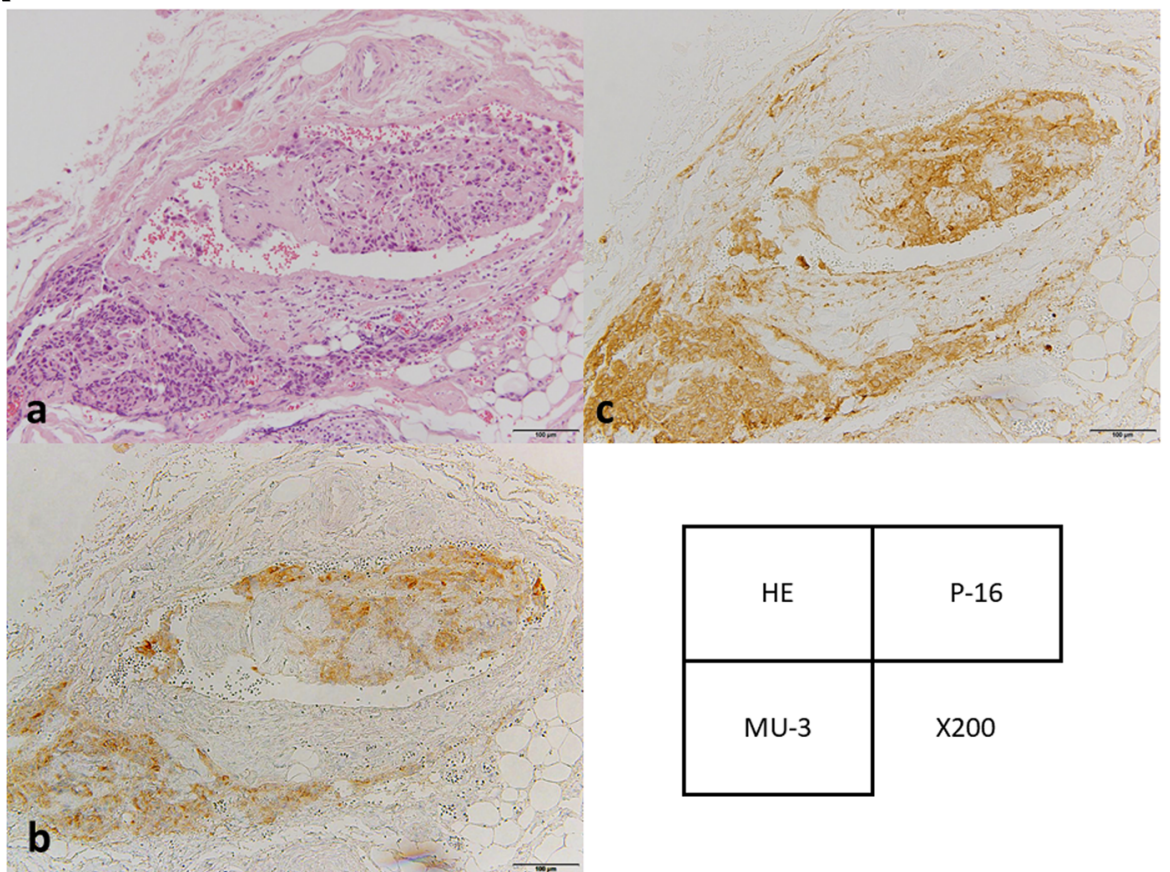

B

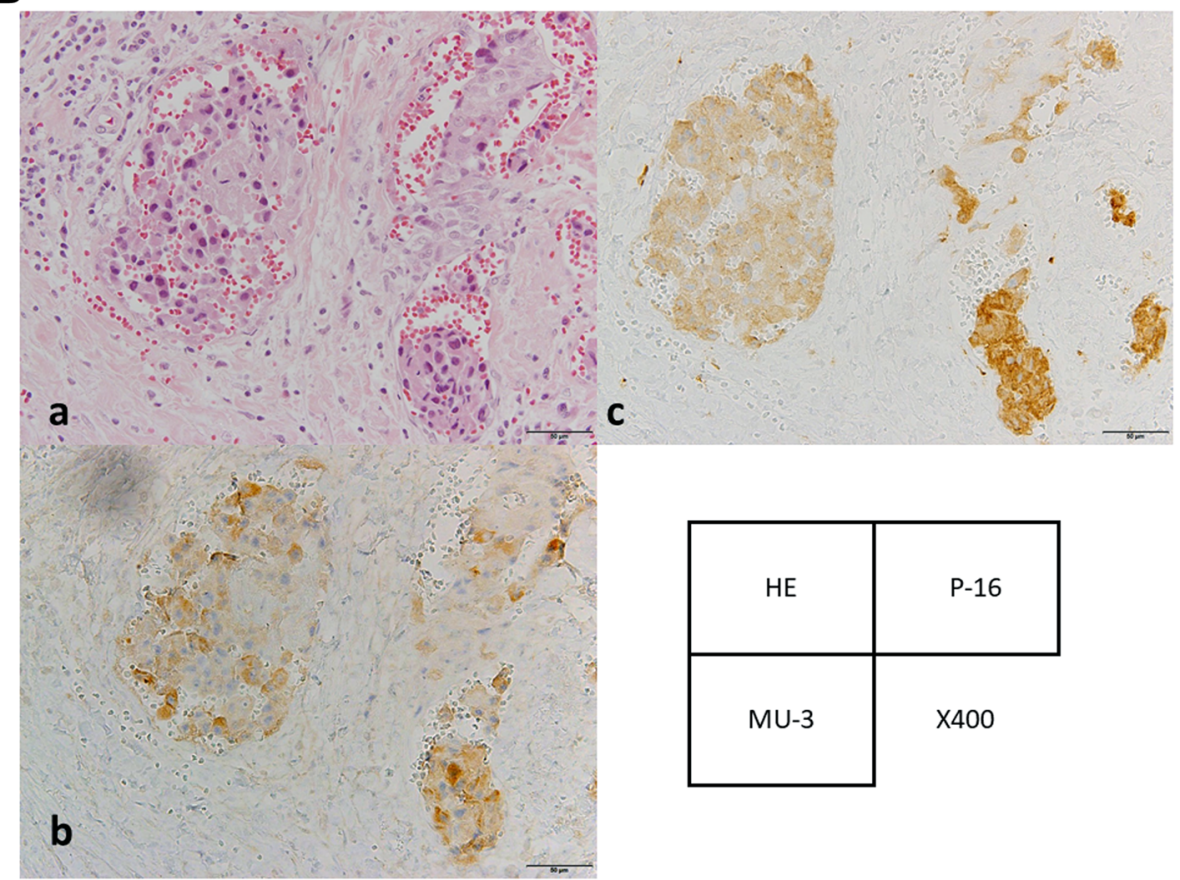

Fig. 2 Immunohistochemical staining for vascular invasion sites. When vascular invasion was identified on HE staining, AFP staining, conventional DCP staining, and NX-DCP. The vascular invasion sites were positive for DCP and NX-DCP but negative for AFP staining. (Original magnification: $2 \mathrm{~A}$ a-c; $\times 200,2 \mathrm{~B}$ a-C; $\times 400$ )

Immunohistostaining of tumor and vascular invasion sites Compared with the negative vascular invasion group, the positive vascular invasion group showed significantly higher levels of conventional DCP [median: $250 \mathrm{mAU} /$
$\mathrm{mL}$ (range: $17-18,790 \mathrm{mAU} / \mathrm{mL}$ ) vs. $31.0 \mathrm{mAU} / \mathrm{mL}$ (16$813 \mathrm{mAU} / \mathrm{mL}$ ), respectively; $p<0.0001]$ and NX-DCP [median: $510 \mathrm{mAU} / \mathrm{mL}$ (range: $10-98,450 \mathrm{mAU} / \mathrm{mL}$ ) vs. $34.0 \mathrm{mAU} / \mathrm{mL}(12-541 \mathrm{mAU} / \mathrm{mL})$, respectively; $\mathrm{p}<$ 
Table 1 Patient characteristics according to vascular invasion

\begin{tabular}{|c|c|c|c|c|}
\hline & & $\begin{array}{l}\text { Positive vascular invasion group } \\
(n=13)\end{array}$ & $\begin{array}{l}\text { Negative vascular invasion group } \\
(n=43)\end{array}$ & $\begin{array}{l}p \\
\text { value }\end{array}$ \\
\hline \multirow[t]{2}{*}{ Gender } & (male) & $7(53.9 \%)$ & $26(60.5 \%)$ & 0.37 \\
\hline & (female) & $6(46.1 \%)$ & $17(39.5 \%)$ & \\
\hline Age & (years) & $70(41-82)$ & $73(43-82)$ & 0.81 \\
\hline HBV infection ${ }^{a}$ & & $4(30.8 \%)$ & $15(34.9 \%)$ & 0.78 \\
\hline HCV infection ${ }^{b}$ & & $8(61.5 \%)$ & $26(60.5 \%)$ & 0.94 \\
\hline Recurrence of hepatocellular carcinoma & & $5(38.5 \%)$ & $13(30.2)$ & 0.58 \\
\hline Aspartate aminotransferase & $(\mathrm{IU} / \mathrm{dL})$ & $31(17-84)$ & $38(14-139)$ & 0.25 \\
\hline Alanine aminotransferase & $(\mathrm{IU} / \mathrm{dL})$ & $26(13-55)$ & $36(12-157)$ & 0.26 \\
\hline Albumin & $(\mathrm{g} / \mathrm{dL})$ & $4.1(3.0-5.0)$ & $4.0(2.8-4.8)$ & 0.36 \\
\hline Total bilirubin & $(\mathrm{mg} / \mathrm{dL})$ & $0.72(0.46-1.46)$ & $0.72(0.26-2.12)$ & 0.94 \\
\hline Prothrombin activity & (\%) & $100(82-100)$ & $100(68-100)$ & 0.78 \\
\hline Platelets count & $\left(\mathrm{mm}^{4} / \mathrm{dL}\right)$ & $15.3(5.8-33.9)$ & $11.5(4.2-22.7)$ & 0.08 \\
\hline Conventional DCP & $(\mathrm{mAU} / \mathrm{mL})$ & $69(8-3549)$ & $22(9-475)$ & 0.04 \\
\hline Next-generation DCP & $(\mathrm{mAU} / \mathrm{mL})$ & $74(17-574)$ & $30(16-813)$ & 0.01 \\
\hline Alpha-fetoprotein & $(\mathrm{ng} / \mathrm{mL})$ & $9.7(1.6-1208.7)$ & $10.6(1.6-453.2)$ & 0.58 \\
\hline Pathological fibrosis grade ${ }^{c}$ & & & & 0.07 \\
\hline f1 & & 4 & 3 & \\
\hline $\mathrm{f} 2$ & & 4 & 9 & \\
\hline f3 & & 1 & 11 & \\
\hline f4 & & 4 & 20 & \\
\hline Pathological hepatitis grade ${ }^{c}$ & & & & 0.33 \\
\hline a1 & & 4 & 13 & \\
\hline a2 & & 4 & 15 & \\
\hline a3 & & 4 & 15 & \\
\hline a4 & & 1 & 0 & \\
\hline Tumor diameter & $(\mathrm{mm})$ & $28(11-50)$ & $22(9-38)$ & 0.06 \\
\hline \multicolumn{5}{|l|}{ Tumor differentiation } \\
\hline Well-differentiated & & $0(0 \%)$ & $9(20.9 \%)$ & 0.02 \\
\hline Modelately differentiated & & $11(84.6 \%)$ & $30(76.7 \%)$ & 0.81 \\
\hline Poorly differentiated & & $2(15.4 \%)$ & $3(7.0 \%)$ & 0.38 \\
\hline Others & & 0 & $1(2.3 \%)$ & 0.41 \\
\hline Fibrous capsule infiltration of tumor & & $6(46.2)$ & $19(44.2)$ & 0.89 \\
\hline
\end{tabular}

${ }^{\mathrm{a}}$ Hepatitis $\mathrm{B}$ virus; ${ }^{\mathrm{b}}$ hepatitis $\mathrm{C}$ virus; ${ }^{\mathrm{C}}$ according to the new Inuyama classification, $D C P$ Des-r-carboxy prothrombin

Table 2 Imunohistostaining of each biomarkers by site $(n=56)$

\begin{tabular}{|c|c|c|c|c|}
\hline Antibody & $\begin{array}{l}\text { Positive vascular invasion group } \\
(n=13)\end{array}$ & $\begin{array}{l}\text { Negative vascular invasion group } \\
(n=43)\end{array}$ & $\begin{array}{l}\text { Total } \\
(n=56)\end{array}$ & $\begin{array}{l}p \\
\text { value }^{a}\end{array}$ \\
\hline \multicolumn{5}{|l|}{ Tumor site } \\
\hline Conventional DCP (MU-3) & $9(69.2 \%)$ & $29(67.4 \%)$ & $38(67.9 \%)$ & 0.90 \\
\hline Next-generation DCP (P-16) & $11(84.6 \%)$ & $34(79.1 \%)$ & $45(80.4 \%)$ & 0.66 \\
\hline \multicolumn{5}{|l|}{ Vascular invasion site } \\
\hline Conventional DCP (MU-3) & $2(15.4 \%)$ & $0(0 \%)$ & $2(3.6 \%)$ & $<0.0001$ \\
\hline Next-generation DCP (P-16) & $6(46.2 \%)$ & $0(0 \%)$ & $6(10.7 \%)$ & 0.0008 \\
\hline Alpha-fetoprotein & $0(0 \%)$ & $0(0 \%)$ & $0(0 \%)$ & 1.00 \\
\hline
\end{tabular}

$D C P$ Des-r-carboxy prothrombin. ${ }^{a}$ Compared between portal vein $(+)$ and pv(-) 
0.0001] (Table 1). In our previous study, the predictive cut-off value for vascular invasion of NX-DCP was 74 $\mathrm{mAU} / \mathrm{mL}$, with a sensitivity of $71.4 \%$, and that of conventional DCP was $66 \mathrm{mAU} / \mathrm{mL}$, with a sensitivity of $71.4 \%$ [17]. In contrast, no relationship was observed for the values of AFP, vascular endothelial growth factor, and vascular endothelial growth factor receptor with or without vascular invasion.

\section{Immunohistostaining grade of tumor and vascular invasion sites}

According to immunohistochemical staining analyses of the original tumor, 38 of 56 patients (67.9\%) showed positive staining for conventional DCP (MU-3), whereas 45 of 56 patients $(80.4 \%)$ showed positive staining for NX-DCP (P-16) (Table 2). No significant differences in staining rates were evident regarding positive or negative for vascular invasion for both conventional DCP and NX-DCP. Among the 13 patients showing pathological portal vein invasion, conventional DCP identified a site of vascular invasion in 2 patients (15.4\%), and NX-DCP identified vascular invasion in 6 patients (46.2\%). In contrast, no patients showed vascular invasion sites with AFP staining. Regarding positive rates for staining, no significant differences were observed at the tumor between conventional DCP and NX-DCP (67.9\% vs. $80.4 \%$, respectively, $p=0.08)$. In contrast, significant differences were seen at sites of vascular invasion $(15.4 \%$ vs. $46.2 \%$, respectively, $p=0.01$ ) (Table 3 ).

\section{Discussion}

This study showed that the results of staining for NXDCP (P-16) show a strong relationship to vascular invasion. Thus, together with our previous study, the serum NX-DCP values might offer accurate prediction of pathological vascular invasion [17].

Vascular invasion is a specific feature of highly invasive $\mathrm{HCC}$ and a predictor of recurrence and survival [7, 18, 20, 23]. Even though small $\mathrm{HCC}$ can be detected with recent advances in imaging modalities, only $10 \%$ of tumors with vascular invasion are detected by radiological diagnosis alone [22, 23]. It has been suggested that DCP offers better diagnostic power for vascular invasion compared to AFP [2, 3, 18-20]. Indeed, our previous study showed that $25.5 \%$ of patients with vascular invasion could be predicted by DCP [17]. Despite several reports on NX-DCP, none has yet confirmed a relationship between NX-DCP and vascular invasion.
AFP is a known tumor marker for $\mathrm{HCC}$, and it has been reported to correlate with tumor diameter and differentiation of $\mathrm{HCC}$ [2-5]. The detection rate of $\mathrm{HCC}$ is $45 \%$ with AFP alone, increasing to more than $60 \%$ in combination with DCP $[2,3,5,17,21]$. However, no previous studies have shown that AFP is useful for detecting deleterious biological properties such as vascular invasion. In our previous study, no correlation was identified between the serum AFP value and vascular invasion [17]. Furthermore, no vascular invasion was positive on AFP staining in the present study. Use of AFP alone is thus insufficient for diagnosing and recognizing the malignant potential of HCC.

Previous studies have shown that NX-DCP levels were correlated with the degree of fibrosis and $\mathrm{HCV}$ infection [9-12]. NX-DCP expression was found in $82 \%$ of noncancerous liver tissues, and overexpression was identified in patients with obstructive jaundice or on warfarin pharmacotherapy [16]. To avoid such false positives, only patients with a single HCC less than $50 \mathrm{~mm}$ in diameter who were not receiving warfarin were examined, and a staining grade based on background parenchyma was used in this immunohistochemical study. As a result, no strong correlations to degree of fibrosis or degree of hepatitis were found pathologically.

Recently, in analyses for gene overexpression, some pathways with microvascular invasion have been divided into low and highly invasive phenotypes associated with two distinct gene-expression profiles [16]. Vascular invasion reflects the biologically aggressive phenotype of $\mathrm{HCC}$, because recurrence is frequent [18-20], and various molecules were up-regulated in the presence of vascular invasion [7, 16, 24, 27]. Tanaka et al. showed two distinct phenotypes in HCC by gene profiling [16]. They showed that the upregulation of the aurora kinase Brelated pathway may be associated with the highly invasive phenotype of HCC by biomolecular network interaction analyses, and overexpression of aurora kinase B protein was confirmed by immunohistochemistry $[16,24]$. In such studies, it was suggested that some component of DCP may be closely associated with the malignant phenotype of HCC. Therefore, further studies to search for biomarkers for the malignant population in HCC may lead to the development of novel, molecular-targeting therapies.

The limitation of this study is the small sample size, and the vascular invasion rates with conventional DCP $(n=2,15.4 \%)$ and NX-DCP $(n=646.2 \%)$ were relatively small; therefore, the relationship between serum blood

Table 3 Rate of positive staining on immunohistochemistry by site

\begin{tabular}{llll}
\hline & Conventional DCP (MU-3) & Next-generation DCP (P-16) & $\boldsymbol{p}$ value \\
\hline Tumor $(n=56)$ & $38(67.9 \%)$ & $45(80.4 \%)$ & 0.08 \\
Vascular invasion site $(n=13)$ & $2(15.4 \%)$ & $6(46.2 \%)$ & 0.01 \\
\hline
\end{tabular}


samples and the results of immunohistochemistry was difficult to determine. Further studies with a larger sample size are needed to resolve this issue. Compared to our previous study, the predictive value of vascular invasion in DCP and NX-DCP is relatively high because of the small sample size [17]. This study showed that the serum levels of conventional DCP and NX-DCP were comparable, and immunohistostaining with both markers was similar in this small cohort, though NX-DCP was more convenient for clinical use because of the lower false-positive rate. Moreover, the positive rate for immunohistostaining at vascular invasion sites was more specific with NX-DCP. Therefore, we believe that NX-DCP may be a useful option for routine clinical use. Regarding planning the treatment strategy, patients with high DCP levels should be alerted to the high risk of vascular invasion, and they are not suitable candidates for radiofrequency ablation (RFA) [23] and should be treat by anatomic resection [21].

\section{Conclusions}

This is the first report to find DCP expression at the site of vascular invasion of $\mathrm{HCC}$ in an immunohistological study. The results of the present study indicate that NXDCP promotes the detection of the future malignant potential of HCC, such as the presence of vascular invasion. However, the patient cohort in this study was too small to allow recognition of the value of NX-DCP. This result is likely to contribute to future research into vascular invasion in HCC.

\section{Abbreviations}

HCC: Hepatocellular carcinoma; DCP: Des-r-carboxy prothrombin; AFP: Alphafetoprotein; NX-DCP: Next-generation DCP

\section{Acknowledgements}

None.

\section{Authors' contributions}

S.Y: study design and writing of the manuscript; T.K*, Y. M, T.H: collection of blood samples and interpretation of data; N.S: performance of statistical examinations; N.Y: support of statistical design; M.S.: pathological evaluation; T.T: organization of study. * Same contribution as S. Y to this study. The author(s) read and approved the final manuscript.

\section{Funding}

None.

\section{Availability of data and materials}

All data were collected and are kept by the corresponding author. Parts of the data are available by contacting the corresponding author.

\section{Ethics approval and consent to participate}

The ethics committee at Nihon University School of Medicine approved this study (reference number: RK-130308-12). Written, informed consent was obtained from all patients. The patient name and ID were hidden and separated to the clinical information to the researcher by random number method

\section{Consent for publication}

Not applicable.

\section{Competing interests}

The authors have no conflicts of interest or financial support to declare in relation to this study.

\section{Author details}

${ }^{1}$ Departments of Digestive Surgery, Nihon University School of Medicine, 30-1 Ohyaguchikami-machi, Itabashi-ku, Tokyo 173-8610, Japan.

${ }^{2}$ Departments of Pathology, Nihon University School of Medicine, 30-1

Ohyaguchikami-machi, Itabashi-ku, Tokyo 173-8610, Japan.

Received: 22 June 2020 Accepted: 6 September 2020

Published online: 14 September 2020

\section{References}

1. Suehiro T, Sugimachi K, Matsumata T, et al. Protein induced by vitamin K absence or antagonist II as a prognostic marker in hepatocellular carcinoma. Comparison with alpha-fetoprotein. Cancer. 1994;73(10):2464-71.

2. Koike $Y$, Shiratori $Y$, Sato $S$, et al. Des-gamma-carboxy prothrombin as a useful predisposing factor for the development of portal venous invasion in patients with hepatocellular carcinoma: a prospective analysis of 227 patients. Cancer. 2001;91(3):561-9.

3. Marrero JA, Su GL, Wei W, et al. Des-gamma carboxyprothrombin can differentiate hepatocellular carcinoma from nonmalignant chronic liver disease in american patients. Hepatology. 2003;37(5):1114-21.

4. Tsukamoto $M$, Nitta $H$, Imai $K$, et al. Clinical significance of half-lives of tumor markers a-fetoprotein and des- $\gamma$-carboxy prothrombin after hepatectomy for hepatocellular carcinoma. Hepatol Res. 2018;48(3):E183-93.

5. Hwang S, Song GW, Lee YJ, et al. Multiplication of tumor volume by two tumor markers is a post-resection prognostic predictor for solitary hepatocellular carcinoma. J Gastrointest Surg. 2016;20(11):1807-20.

6. Chen H, Chen S, Li S, et al. Combining des-gamma-carboxyprothrombin and alpha-fetoprotein for hepatocellular carcinoma diagnosing: an update meta-analysis and validation study. Oncotarget. 2017:8(52):90390-401.

7. Ma XL, Zhu J, Wu J, et al. Significance of PIVKA-II levels for predicting microvascular invasion and tumor cell proliferation in Chinese patients with hepatitis B virusassociated hepatocellular carcinoma. Oncol Lett. 2018;15(6):8396-404.

8. Tanaka S, Mogushi K, Yasen M, et al. Gene-expression phenotypes for vascular invasiveness of hepatocellular carcinomas. Surgery. 2010;147(3):405-14.

9. Tanaka T, Taniguchi T, Sannomiya K, et al. Novel des- $\gamma$-carboxy prothrombin in serum for the diagnosis of hepatocellular carcinoma. J Gastroenterol Hepatol. 2013;28(8):1348-55.

10. Nanashima A, Abo T, Taura N, et al. NX-PVKA levels before and after hepatectomy of hepatocellular carcinoma as predictors of patient survival a preliminary evaluation of an improved assay for PIVKA-II. Anticancer Res. 2013;33(6):2689-98.

11. Tameda M, Shiraki K, Sugimoto K, et al. Des- $\gamma$-carboxy prothrombin ratio measured by $\mathrm{P}-11$ and $\mathrm{P}-16$ antibodies is a novel biomarker for hepatocellular carcinoma. Cancer Sci. 2013;104(6):725-31.

12. Toyoda H, Kumada T, Osaki Y, et al. Novel method to measure serum levels of des-gamma-carboxy prothrombin for hepatocellular carcinoma in patients taking warfarin: a preliminary report. Cancer Sci. 2012;103(5):921-5 Am J Gastroenterol 2004;99(8):1470-1476.

13. Takeji S, Hirooka M, Koizumi Y, et al. Des-gamma-carboxy prothrombin identified by $\mathrm{P}-11$ and P-16 antibodies reflects prognosis for patients with hepatocellular carcinoma. J Gastroenterol Hepatol. 2013;28(4):671-7.

14. Miyahara K, Nouso K, Morimoto Y, et al. Evaluation of the effect of sorafenib using serum NX-des- $\gamma$-carboxyprothrombin in patients with hepatocellular carcinoma. Hepatol Res. 2013;43(10):1064-70.

15. Hirano H, Saito M, Seo Y, et al. NX-DCP as a novel biomarker would be related to liver function in cirrhotic patients with hepatocellular carcinoma. Eur J Gastroenterol Hepatol. 2013;25(6):748-9.

16. Sumi A, Akiba J, Ogasawara S, et al. Des- $\gamma$-carboxyprothrombin (DCP) and NX-DCP expressions and their relationship with clinicopathological features in hepatocellular carcinoma. PLoS One. 2015;10(3):e0118452.

17. Kurokawa T, Yamazaki S, Mitsuka $Y$, et al. Prediction of vascular invasion in hepatocellular carcinoma by next-generation des-r-carboxy prothrombin. Br J Cancer. 2016;114(1):53-8.

18. Adachi E, Maeda T, Kajiyama K, et al. Factors correlated with portal venous invasion by hepatocellular carcinoma: univariate and multivariate analyses of 232 resected cases without preoperative treatments. Cancer. 1996;77(10):2022-31. 
19. Shirabe K, Itoh S, Yoshizumi T, et al. The predictors of microvascular invasion in candidates for liver transplantation with hepatocellular carcinoma-with special reference to the serum levels of des-gamma-carboxy prothrombin. J Surg Oncol. 2007;95(3):235-40.

20. Hirokawa F, Hayashi M, Miyamoto Y, et al. Outcomes and predictors of microvascular invasion of solitary hepatocellular carcinoma. Hepatol Res. 2014;44(8):846-53.

21. Imamura H, Matsuyama Y, Miyagawa Y, et al. Prognostic significance of anatomical resection and des-gamma-carboxy prothrombin in patients with hepatocellular carcinoma. Br J Surg. 1999;86(8):1032-8.

22. Takayama T, Makuuchi M, Kojiro M, et al. Early hepatocellular carcinoma: pathology, imaging, and therapy. Ann Surg Oncol. 2008;15(4):972-8.

23. Asaoka $Y$, Tateishi R, Nakagomi R, et al. Frequency of and predictive factors for vascular invasion after radiofrequency ablation for hepatocellular carcinoma. PLoS. 2014:9(11):e111662.

24. Tanaka S, Arii S, Yasen M, et al. Aurora kinase B is a predictive factor for aggressive recurrence of hepatocellular carcinoma after curative hepatectomy. Br J Surg. 2008;95(5):611-9.

25. Wang K, Liu J, Yan ZL, et al. Overexpression of aspartyl-(asparaginyl)-betahydroxylase in hepatocellular carcinoma is associated with worse surgical outcome. Hepatology. 2010;52(1):164-73.

26. Ichida F, Tsuji T, Omata M, et al. New Inuyama classification for histological assessment of chronic hepatitis. Hepatol Commun. 1996;6:112-9.

27. Liu S, Guo W, Shi J, et al. MicroRNA-135a contributes to the development of portal vein tumor thrombus by promoting metastasis in hepatocellular carcinoma. J Hepatol. 2012;56(2):389-96.

\section{Publisher's Note}

Springer Nature remains neutral with regard to jurisdictional claims in published maps and institutional affiliations.

Ready to submit your research? Choose BMC and benefit from:

- fast, convenient online submission

- thorough peer review by experienced researchers in your field

- rapid publication on acceptance

- support for research data, including large and complex data types

- gold Open Access which fosters wider collaboration and increased citations

- maximum visibility for your research: over $100 \mathrm{M}$ website views per year

At $\mathrm{BMC}$, research is always in progress.

Learn more biomedcentral.com/submissions 